\title{
A sensitive single reverse passive haemagglutination test for detecting both HBsAg and anti-HBs
}

\author{
J. A. J. BARBARA, P. J. HARRISON, D. R. HOWELl, T. E. ClEGHORN, \\ D. S. DANE, MOYA BRIGGS, AND C. H. CAMERON
}

From the North London Blood Transfusion Centre, Edgware, Middlesex. and the Department of Virology, The Middlesex Hospital, London, UK

SUMMARY A trial of a modified reverse passive haemagglutination test for HBsAg using a $0 \cdot 1 \%$ cell suspension instead of the recommended $1 \%$ showed an approximately eight-fold increase in detection sensitivity. The test can be performed within 30 minutes and lends itself to mass screening techniques. Confirmation tests can be done using the $0.1 \%$ method. In addition, the same serological plates and cells used for HBsAg screening can then be used to screen for high-titre anti-HBs. This makes the overall screening for both HBsAg and high-titre anti-HBs donors cheap and convenient.

In a previous communication (Barbara et al., 1977), we compared passive haemagglutination (RPHA) ${ }^{1}$ with radioimmunoassay (RIA) for HBsAg screening. We have now made an extensive trial of a modified RPHA based on the method of Archer (1977). The modification involves the use of $0.1 \%$ test cells (Archer used $0.2 \%$ cells), instead of the usual $1 \%$, and is more sensitive than ordinary Hepatest. We shall refer to the modified test as ' $0 \cdot 1 \%$ Hepatest' and the standard test as ' $1 \%$ Hepatest' throughout. It can be performed within 30 minutes, and unconfirmable positive screen tests are no more common than with $1 \%$ Hepatest. It is slightly more complicated to perform but lends itself well to semiautomated sampling (Cameron and Barbara, 1978) and has the added advantage that plates used for HBsAg screening can also be used afterwards for anti-HBs screening without the need for further sampling or further reagents other than a diluted HBsAg positive serum.

Before the present trial, which was performed in stages, we had been screening all donations for HBsAg by $1 \%$ Hepatest. Those from previously untested donors were also tested by RIA (Barbara et al., 1977). In the first stage of the trial, $0 \cdot 1 \%$ Hepatest was added as a third test for new donors. After three months we were satisfied that it was reliable and used it as the only RPHA method for new donor screening. After a further three months we changed from $1 \%$ Hepatest to $0 \cdot 1 \%$ Hepatest for

${ }^{1}$ Hepatest, Wellcome Reagents Limited, Beckenham, UK

Received for publication 18 April 1979 screening previously tested donors. We are now able to report 13 months' experience of screening new donors by $0.1 \%$ Hepatest in parallel with RIA, and 7 months' experience of screening all donations by $0 \cdot 1 \%$ Hepatest.

\section{Material and methods}

BLOOD DONORS

Donors were classified as old (previously screened) or new, as described previously (Barbara et al., 1977).

\section{RIA for $H B s A g$}

The Middlesex Hospital technique was used (Heathcote et al., 1974; Barbara et al., 1977). Detection sensitivity was $1 \mathrm{ng} / \mathrm{ml} \mathrm{HBsAg}$.

\section{RPHA}

Donations were screened against test cells at a 1 in 8 serum dilution (Cameron and Barbara, 1978) by $1 \%$ Hepatest (Cayzer et al., 1974) and/or by $0.1 \%$ Hepatest.

For $0.1 \%$ Hepatest the test and control cells were reconstituted to a $1 \%$ concentration in distilled water containing $0.1 \%$ sodium azide. These were stored frozen in $1 \mathrm{ml}$ aliquots, thawed when needed, and diluted to $0.1 \%$ in buffer. Hepatest buffer (Cayzer et al., 1974) with $2 \%$ turkey serum added was dispensed into 96-well V-bottomed microtitre plates (Sterilin Limited, Teddington, Middlesex, UK). Serum from donors was screened with test cells at a 1 in 8 dilution using a semiautomatic sampler (Cameron and Barbara, 1978). After the addition of 


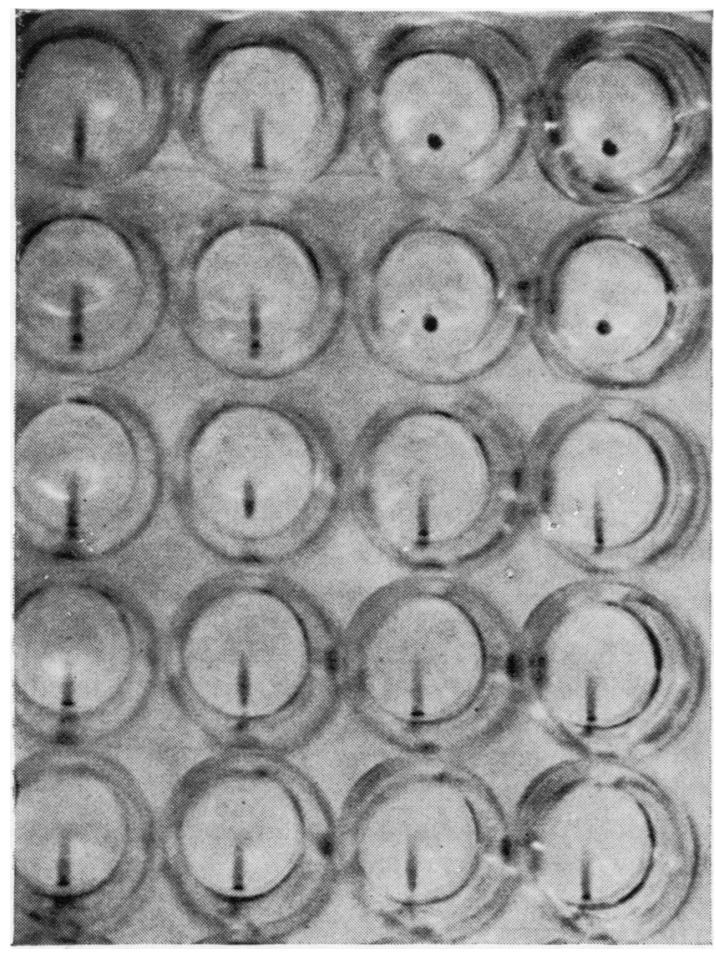

Fig. 1 One corner of Microtitre plate showing the four positive controls (tight buttons) and the negative screen tests (teardrop streaks) 8 minutes after inclining the centrifuged plate at $70^{\circ}$.

one drop $(25 \mu \mathrm{l})$ of $0.1 \%$ test cells to each well the plate was covered, left on the bench for 10 minutes, and then centrifuged in an MSE mistral 6L (with an $M / 19$ head) for 40 seconds at $260 \mathrm{~g}$, which is just sufficient to cieposit the cells in tight buttons at the bottom of the $\mathrm{V}$ wells. The plate was then inclined at $70^{\circ}$ over an illuminated background and read after 5 to 10 minutes. In samples containing $\mathrm{HBsAg}$, the cells stayed as tight buttons in the bottom of the wells whereas with negative samples they ran down the side of the well, forming a smooth teardrop streak (Fig. 1). All screen test positives were titrated and confirmed by neutralisation, as previously described (Cayzer et al., 1974; Barbara et al., 1977). In the confirmation test using $0.1 \%$ Hepatest, dilutions were made using a multichannel Titertek pipette (Flow Laboratories Limited, Irvine, UK) with disposable plastic tips to avoid scratching the plastic wells.

Plasma samples often gave a false-positive screen test unless first absorbed with $10 \%$ control cells for half an hour or treated with kaolin (Light, BDH Limited, Poole, Dorset, UK) at $0.1 \mathrm{~g} / \mathrm{ml}$ plasma. Serum samples should be stored at $4^{\circ} \mathrm{C}$ or frozen, as bacterial growth can cause non-specific agglutination. Care must be taken to avoid carrying over red cells during serum sampling as these may cause a falsepositive screen test.

The different RPHA and RIA tests were all read separately, and all HBsAg positives detected were confirmed and subtyped by RIA, as described previously (Heathcote et al., 1974).

TESTING FOR ANTI-HBS

After the $0.1 \%$ Hepatest for HBsAg had been read the plates were centrifuged once more to deposit the test cells, and one drop $(25 \mu \mathrm{l})$ of diluted, heattreated HBsAg positive serum was added to each well. Heat treatment was to reduce infectivity; after an initial 1 in 4 dilution in saline, the positive serum was heated in a waterbath at $60^{\circ} \mathrm{C}$ for 10 hours and then diluted to contain two complete haemagglutinating doses of $\mathrm{HBsAg}$ per $25 \mu \mathrm{l}$. The plates, with cell buttons undisturbed, were left overnight at $4^{\circ} \mathrm{C}$. In the morning the cells were resuspended using an AM 60 Cooke Microshaker (Dynatech Laboratories Limited, Sussex, UK) and left at room temperature for 30 minutes. The test procedure was then as for the $0.1 \%$ Hepatest RPHA for $\mathrm{HBsAg}$ although the reading of positives was reversed; cells in the samples containing anti-HBs formed a teardrop streak whereas cells in samples negative for anti-HBs remained in tight buttons. The same principle was used for detecting anti-HBs after the $1 \%$ Hepatest for $\mathrm{HBs} \mathrm{Ag}$; in this instance the plates were read after the resuspended cells had settled in the usual fashion.

\section{HBSAg DETECTION RATES}

The rates of $\mathrm{HBsAg}$ detection in new and old donors are shown in the Table. Eleven per cent more HBsAg positive new donors were found using RIA than were found using $1 \%$ Hepatest, which was the same as we had found previously (Barbara et al., 1977). This increment was reduced to $6 \%$ using $0 \cdot 1 \%$ Hepatest. About $5 \%$ of new donors were from countries with high HBsAg carrier rates, and 22 $(42 \%)$ of the $52 \mathrm{HBsAg}$ positive new donors were from these areas. During the 13-month period, 156200 old donors were screened by one or other of the RPHA techniques, and four were found to be $\mathrm{HBs} \mathrm{Ag}$ positive, giving an incidence of 1 in 39000 .

FOLLOW-UP OF HBSAg POSITIVE DONORS

Of $56 \mathrm{HBsAg}$ positive donors, the four who were old donors all had acute anicteric hepatitis B. We were able to resample 43 of the remaining 52 , and of these, six had acute infections although only one was icteric. Two of the three $\mathrm{HBsAg}$ positive donors, 


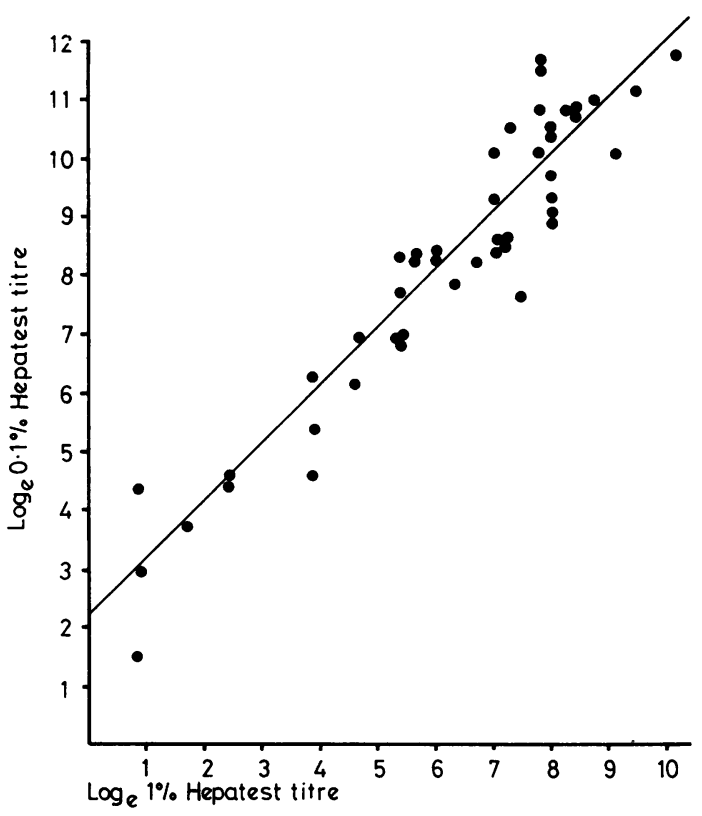

Fig. 2 Parallel titrations of HBsAg-positive samples by $1 \%$ Hepatest and $0.1 \%$ Hepatest.

who could be detected by RIA only, had acute infections; no follow-up sample was available from the other one.

\section{DETECTION SENSITIVITY OF}

$0 \cdot 1 \%$ HEPATEST COMPARED WITH

$1 \%$ HEPATEST

Figure 2 illustrates the increased sensitivity of $0 \cdot 1 \%$ Hepatest over $1 \%$ Hepatest when 48 samples with different titres of $\mathrm{HBsAg}$ were titrated by both methods in parallel. The graph was plotted on natural logarithmic scales to encompass the full range of titres, and the best straight line was found by regression. The intercept on the logarithmic ordinate converted to an approximately eightfold increment in sensitivity. The slope of the best straight line was $1 \cdot 0$. Half of the 48 samples were subtype $a d$ and half were $a y$.

The increased sensitivity of $0 \cdot 1 \%$ Hepatest over the $1 \%$ test resulted in two additional $\mathrm{HBsAg}$ positive new donors being found in 25200 screened (see Table).

\section{VARYING TEST CONDITIONS}

FOR $0 \cdot 1 \%$ HEPATEST

When test cells were added to the test serum dilutions, maximum sensitivity was reached after 10 minutes' incubation on the bench. Shaking the plate during
Table Blood donor screening January 1977 to January 1978

\begin{tabular}{|c|c|c|c|c|}
\hline Donors & Period & $\begin{array}{l}\text { No. } \\
\text { tested }\end{array}$ & $\begin{array}{l}\text { No. HBsAg positive } \\
\text { by different tests }\end{array}$ & $\begin{array}{l}\text { Incidence of } \\
\text { HBsAg positive } \\
\text { donors }\end{array}$ \\
\hline New & $\begin{array}{l}\text { Jan } 1977 \\
\text { to Jan } 1978\end{array}$ & 25200 & $\begin{array}{r}1 \% \text { Hepatest : } 47 \\
0.1 \% \text { Hepatest : } 49 \\
\text { RIA : } 52\end{array}$ & $\begin{array}{l}1 \text { in } 536 \\
1 \text { in } 514 \\
1 \text { in } 485\end{array}$ \\
\hline Old & $\begin{array}{l}\text { Jan } 1977 \\
\text { to Jun } 1977 \\
\text { Jul } 1977 \\
\text { to Jan } 1978\end{array}$ & $\begin{array}{l}72000 \\
84200\end{array}$ & $\begin{array}{c}1 \% \text { Hepatest: } 2 \\
0 \cdot 1 \% \text { Hepatest: } 2 *\end{array}$ & $\begin{array}{l}1 \text { in } 36000 \\
1 \text { in } 42100\end{array}$ \\
\hline
\end{tabular}

*One of these could be detected by $1 \%$ RPHA.

this period did not increase sensitivity, nor did incubation at $37^{\circ} \mathrm{C}$.

The speed and time of centrifugation of plates and the angle of slope of the plates can be adjusted to suit the operator. The conditions stated in Material and methods provide a reading within 5 to 10 minutes with most batches of cells tested. This means a total test time of 20 minutes. The $2 \%$ turkey serum added to the Hepatest buffer is necessary in the $0.1 \%$ method to keep the number of false-positive screen tests down to approximately $1 \%$.

OTHER CONSIDERATIONS IN THE

USE OF $0.1 \%$ HEPATEST

Bacterial contamination of serum samples causes diffuse non-specific agglutination, and neither streaks nor buttons are seen.

The false-positive effect caused by plasma in $1 \%$ Hepatest is enhanced using the $0.1 \%$ method but can be absorbed out.

Screen test false-positives occurred at the same rate as with $1 \%$ Hepatest (approximately 1 per 96well microtitre plate) and could be identified as such by confirmation testing.

No prozoning was observed when very high titre subtype ad and ay samples were titrated by $0 \cdot 1 \%$ Hepatest.

\section{ANTI-HBS SCREENING}

Of 10250 new and old donors randomly tested by the $0.1 \%$ Hepatest HAI, 78 screen test positives were picked out; these included poss'ble weak positive reactions as well as clearcut positives. Thirty-six were found to be known anti-HBs positive donors, and of the remaining 42,32 were confirmed positive by an RIA blocking test for anti-HBs, and half of these were detectable using the less sensitive $1 \%$ Hepatest HAI.

\section{Discussion}

Hepatest using $0 \cdot 1 \%$ cells has proved a convenient, 
sensitive, and economical test and is now the routine method of screening for HBsAg at NLBTC although new donors are also tested by RIA. The approximately eightfold increase in detection sensitivity resulted in a modest $4 \%$ increment in the number of $\mathrm{HBs} \mathrm{Ag}$ positive donors discovered.

The use of the $0.1 \%$ Hepatest HBsAg screening plates for anti-HBs testing was also economical and convenient, as the serum sampling had already been done and no further cells were required. We now use it routinely to maintain a panel of anti-HBs positive donors for anti-HBs immunoglobulin production. Anti-HBs of sufficient strength to be detected by immunodiffusion could be found readily by the $0.1 \%$ HAI test. The test can be made less sensitive by altering the concentration of $\mathrm{HBsAg}$ added to the wells. The donors with higher titre anti-HBs could be detected by the $1 \%$ HAI test.

Buffer suitable for $1 \%$ Hepatest is not necessarily suitable for the $0.1 \%$ test using the same batch of cells and must be checked for suitability with the latter test. This variability has been due to so far undefined qualities of the human, horse, and turkey serum used in the buffer. Also some batches of cells may not lend themselves as well as others to the $0 \cdot 1 \%$ test.

The finding of only four HBsAg positive donations, all of which came from donors with acute hepatitis B infections, among 156200 previously screened donors indicates that these donors have a very low incidence of acute hepatitis $B$ infection and that our screening of new donors is efficient. Anicteric acute infections were considerably more common than icteric infections. In a total of $47 \mathrm{HBsAg}$ positive donors from whom we had follow-up samples of blood, 10 had acute infections but only one was jaundiced. Donors who had recently had jaundice would not qualify to donate even if they felt well enough, and this may have increased the proportion of anicteric infections found.

We thank Mr P Mochnaty for Figure 1.

\section{References}

Archer, A. C. (1977). An improved haemagglutination technique for the detection of hepatitis Bs antigen. Medical Laboratory Sciences, 34, 345-350.

Barbara, J. A. J., Howell, D. R., Cleghorn, T. E., Cameron, C. H., Briggs, M., and Dane, D. S. (1977). A comparison of different methods of screening blood donations for HBsAg. Vox Sanguinis. 32, 4-9.

Cameron, C. H., and Barbara, J. A. J. (1978). A multıple sampling device for the mass screening of serum samples for hepatitis B surface antigen. Journal of Clinical Pathology, 31, 288-291.

Cayzer, I., Dane, D. S., Cameron, C. H., and Denning, J. V. (1974). A rapid haemagglutination test for hepatitis-B antigen. Lancet, 1, 947-949.

heathcote, J., Cameron, C. H., and Dane, D. S. (1974). Hepatitis-B antigen in saliva and semen. Lancet, 1, 71-73.

Requests for reprints to: Dr J. A. J. Barbara, National Blood Transfusion Service, North London Blood Transfusion Centre, Deansbrook Road, Edgware, Middlesex HA8 9BD, UK. 